\section{The Vessel, the Tower, and the Ruin: Investigating Presentiments in Beginning Design}

Kristen Kelsch

Louisiana State University

Joss Kiely

Louisiana State University

Anca Matyiku

Louisiana State University
The Vessel, the Tower, and the Ruin was a sequence of exercises which combined rudimentary elements of an architectural education with tactics that oscillated between the impulsive provocation of hunches, to the ascetic discipline of rigorous measurement, to exploiting curiosities and flirting with collapse. [1] We probed, at times in earnest and at times irreverently, what it might mean to vessel, to tower, and to ruin. We took this both literally, figuratively, metaphorically and everything in between, and we enlisted a motley crew of accomplices, some dignified by history, photography, and made famous by dynamite, and others of questionable constitution and architectural import. We operated under the premise that students of design, at the outset, need to engage their own curiosities, speculations, and urges within a framework that affords them a level of guidance while promoting individual freedom and initiative. Through and through the studio was laced with questions about creative agency and architecture's participation within an expanded continuum of time, history, cultural aspirations and politics.

\section{AN OVERVIEW: DESIGN STUDIO AS A SERIES OF PRODUCTIVE COLLISIONS}

We set out to craft a studio which expanded upon the basic fundamentals of a beginning design education. Over the course of the semester, we challenged students' inveterate notions of space and form by alternating between media and engaging materials that are largely considered outside of the discipline. In the process, we moved back and forth between scales and shifted the level of intimacy between the student and their engagement with the situation and materials of their projects.

We introduced the basic fundamentals of projection and section cuts at one-to-one scale, by asking students to each work with one of several cucurbitaceae specimens-also known as winter squash. The squash was seen as an excellent opportunity to introduce beginning design students to an essential architectural lesson, namely the interplay between object and space, boundary and atmospheric qualities. The process was presented to students as an articulation of space via a thoughtful disarticulation of the squash. The squash's inherent entropy played an additional interference to this dialectic of making and unmaking, thus bringing to the fore notions about time and creative agency. A second exercise expanded on the fundamentals of section and projection by asking students to produce a disciplined drawing set of a water tower, chosen from a selection taken by photographers Bernd and Hilla Becher who are well known for their technique of photographing industrial relics with a near-head-on perspective. While the students worked again at one-to-one with a copy of the photograph, they were nudged towards the notion of the architectural drawing as a scaled artifact. Reiterating the emphasis on spatial qualities, students were asked to produce a spatial collage within their vertical section drawing. This exercise was precipitated by a reading of Antonio Sant'Elia Futurist Manifesto and later served as the basis for a retroactive manifesto of each students' spatial collage. Thus, beginning design fundamentals were productively collided with architectural history, by playfully positioning students' own design ambitions within architectural history, more specifically within the 


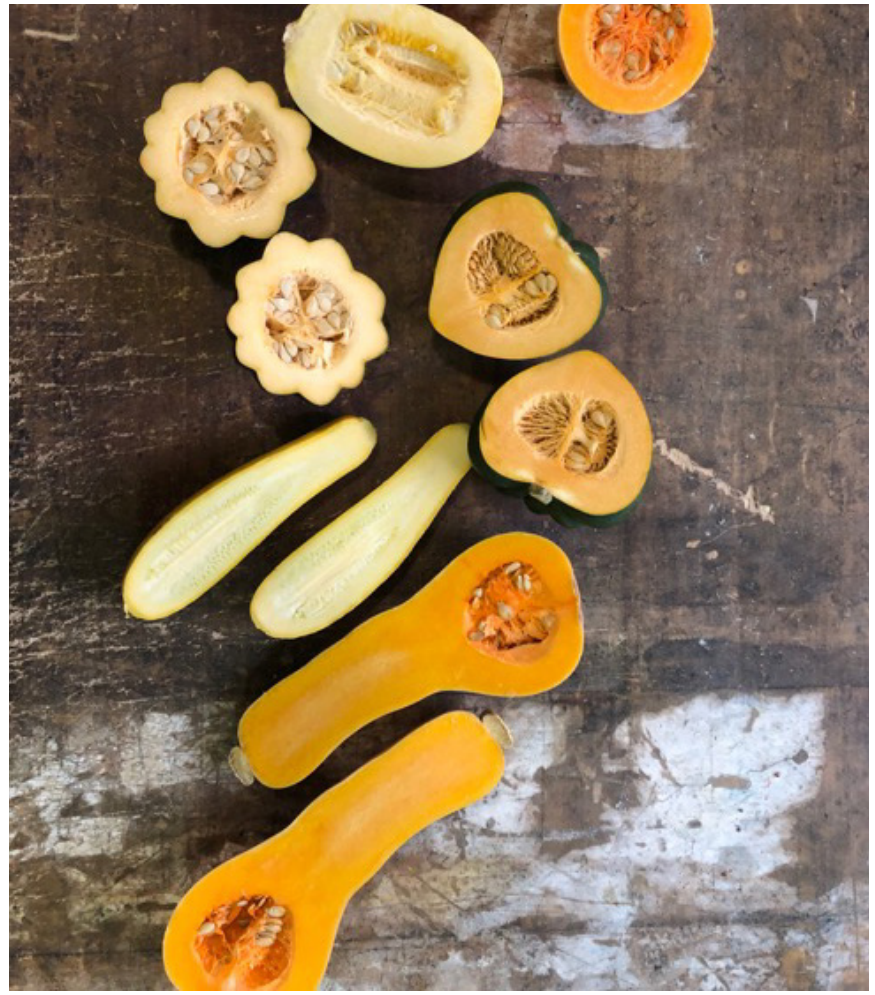

Figure 1. The Specimens. (Photograph by authors)

history of architectural futures. These first few provocations, while seemingly disparate, operated as primers for the final set of exercises which revolved around Kirby Smith Hall, a modernist student residence on LSU's campus, slated to be demolished in 2020. [2] Thus, Kirby Smith Hall offered a one-of-a-kind opportunity to situate the students' very first architectural design within the broader continuum of the history of modernist architectural ambitions, their social and political aspirations, their eventual failure, and the subsequent demise of architectural projects deemed no longer adequate by shifting value systems-despite their otherwise unproblematic functionality or sound structural integrity. Kirby Smith Hall became both muse and antagonist, and the perfect pretext for a first stab at beginning-design space-making that also thrust students to vessel, to tower, and then to ruin, productively colliding them with the inevitable fate of the architectural specimen which some of them called home for at least a semester or two. We relied on our instructor hunches and trusted that it is never too early to expose students to architecture's entanglements with forces both global and place-specific, not even while introducing them to the rudiments of scaled drawings, scaled models, and representation techniques. We moved from working at a scale of one-to-one (at the start of the semester), to one-to-one-quarter scale (by the end of the semester). Elemental architectural basics were positioned within an expanded continuum of issues that remain central to architectural design and discourse-including architectural history and awareness of a cultural context, as well as notions of time, selective decay, the architectural event and collapse. We approached these elemental lessons as "productive collisions" that were infiltrated with opportunities for students to consider different modes of failure, collapse, decay and entropy and how these play into questions of design agency. In architectural education, we spend a great deal of time exploring the idea of "making" or "becoming," that is, the act of martialing materials and abstract ideas into physically and metaphorically occupiable spaces. But what we don't often discuss is what happens when a building, project, or intervention fails to meet the needs or demands placed upon it, when it outlives its utility, or when society and the capitalist mechanism deems it no longer as productive as that which might replace it. As a result, our studio investigation turned toward what we deemed the fast unbecoming, that is, an architectonic demolition.

In what follows we expand on those moments in the semester's arc that may be considered the more daring tactics in beginning design, and those that most acutely solicited the trusting of our instructors hunch. We have referred to these tactics and instances as "productive collisions" for all involved.

\section{SQUASH}

As noted, a first means to break from conventional approaches to beginning design, was the choice of winter squash as an opportunity for an initial spatial investigation. (Figure 1) The range of squash assigned to students included acorn, butternut, delicata, kabocha, and confet-ti, among others-each with a distinct external aesthetic and internal logic. We worked from the assumption that students from Louisiana, while very familiar with summer squash varieties that frequently appear in the culinary traditions of the region, would be far less famil-iar with their winter brethren. Moreover, it seemed highly unlikely any students had previously considered these unfamiliar squash as having significant spatial properties. The variable interior condition of each squash variety produced a literal cross section of surprising spatial qualities-long and narrow, fat and round, irregular or "misshapen"-that challenged students preconceived ideas of what the "interior" might have looked like. (Figure 2) During the process, students drew and re-drew their specimen, which provided ample early opportunity to reinforce the powers and the lies of projection with an unusual "spa-tial" object. (Figure 3) In this sense, we were working with familiar objects (readily available vegetables) to explore them as unfamiliar territories (in other words, the possible "architecture" of a squash).

During the planning process, we quickly realized that the acorn squash, sometimes referred to as the Des Moines squash, was perhaps the consummate specimen to illustrate the often difficult distinction between plan and section, or between horizontal section and vertical section. When an acorn squash is cut vertically along one of the eleven bands that comprise its flesh and skin, the section cut appears smooth and almost heart-shaped. Conversely, the lateral cut exposes a beautifully rhythmic pattern that appears nearly scalloped on the exterior, while the interior has a smoother, more rounded appearance. This split relationship between vertical and horizontal section cuts both illustrated a clear architectural phenomenon while avoiding architecture in the traditional sense entirely. The winter squash performed as a vessel that carried through core architectural 


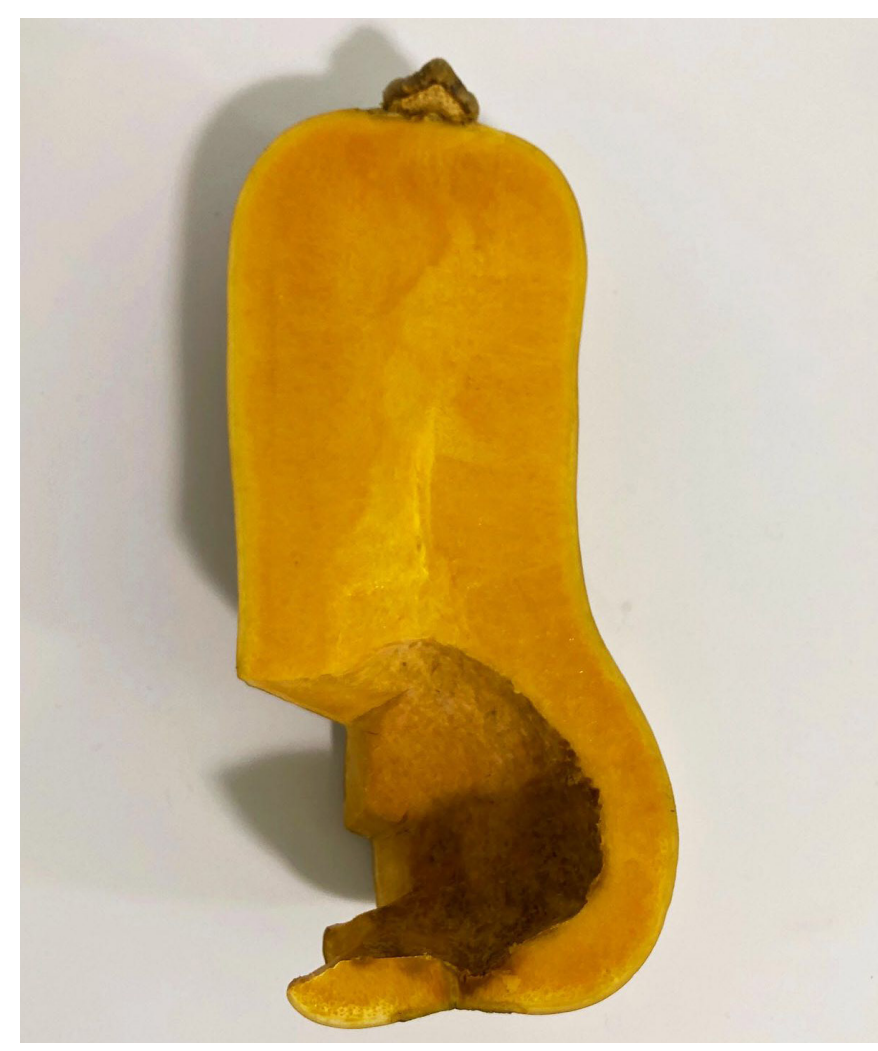

Figure 2. A disarticulated squash. (Photograph by ARCH 1002 student)

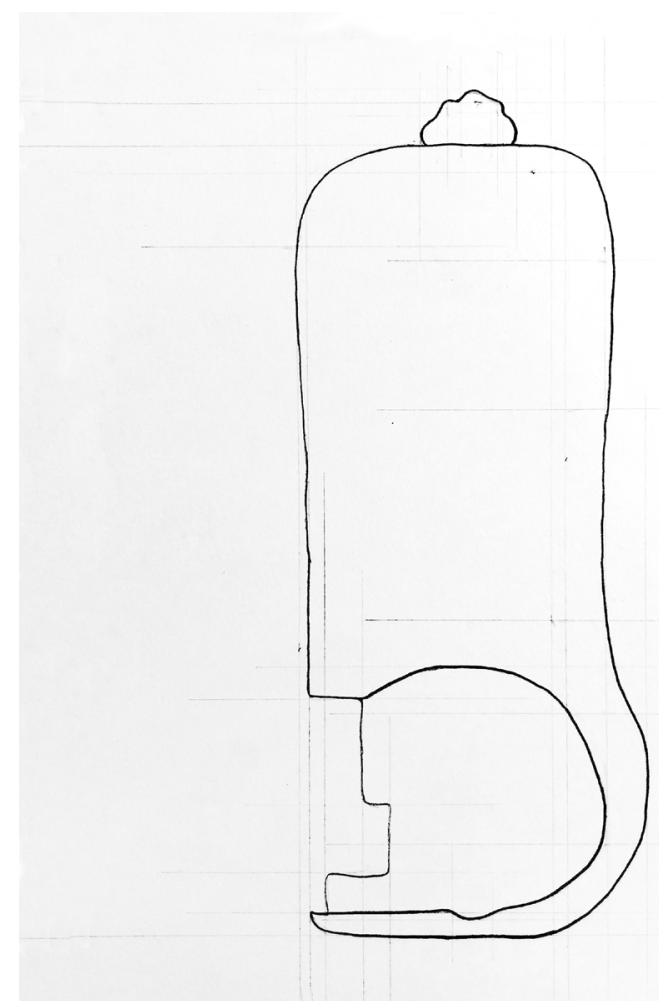

Figure 3. Student work: orthographic section of disarticulated squash. (Scan by ARCH 1002 student) principles while challenging students to think beyond what might even be considered architecture, such as a building. In other words, the "as-found" condition of the squash as vessel operated as a vehicle to simultaneously introduce and challenge ideas of space, one of a series of "productive collisions" presented throughout the semester.

The task then turned from understanding the winter squash as a vessel of space, to one which asked them to begin the slow process of turning it, quite literally, into a ruin. In the process, students hastened the slow unbecoming of latent decay by making a series of cuts, extractions, and incisions in their specimen, until the squash was transformed into a kind of "decomposed other." After careful extraction and deliberation over several days, students were ultimately tasked with making a definitive section cut. This effectively furthered the entropic forces of disintegration and decay, which were recorded through numerous drawings and photographs.

This slow unbecoming marked a first register of temporality and the idea of "event," architectural and otherwise, which laid the groundwork for discussions of time, becoming, and unbecoming as core operations in architectural production and its literal un-production that would continue over the course of the semester. It was our intent that working with slightly unconventional as-found objects, we could foreground a low-tech yet high-impact relationship between physical object and beginning architectural understandings.

\section{KIRBY'S ARTICULATE BECOMING}

In the final portion of the studio, we explored notions of fixity and transience in the built environment through an interrogation of Kirby Smith Hall, a modernist tower on campus in which a handful of the students resided. (figs. 4 and 5). We found a unique opportunity in working with Kirby Smith due to its slated demolition at the close of the semester. This, it seemed, was a felicitous chance to probe students to consider notions of time, decay, and collapse at a very early stage in their design education. Furthermore, we positioned Kirby Smith within the extended continuum of architectural history by contextualizing its demolition in relation to the Pruitt-Igoe Public housing project in St. Louis, its well known "failure" to deliver on the promised modernist ideals, and its rather spectacular demolition. This portion of the project was launched with a viewing of the demolition of Minoru Yamasaki's Pruitt-lgoe Public Housing project and a discussion of excerpts from Charles Jencks' The Language of Postmodern Architecture (1977). We pointed out that, although Yamasaki was an incredibly prolific contributor to the built environment during the latter half of the twentieth century, his legacy has been marked by two of the most infamous architectural disasters: the demolition of PruittIgoe and the destruction of the World Trade Center.

We further noted that, a once-touted solution to affordable public housing, the Pruitt-Igoe Public Housing project quickly decayed after its 1956 completion, due to a lack of funding from the federal Housing and Urban Development (HUD) office and its failure to deliver on promised ideals-dimly echoing architectural modernism and CIAM planning principles that never figured prominently in the logistical planning of US public housing at this time. A combination of disrepair and an increase in gang-related violence rendered the projects 
increasingly difficult to control. This resulted in a rapidly deteriorating situation, both physically and socially, such that the buildings were demolished in 1972. Only then did they become well known within the chronicles of architectural history and theory, when Jencks associated their demise with the end of architectural modernism:

Happily we can date the death of modern architecture to a precise moment in time. Unlike the legal death of a person...modern architecture went out with a bang. That many people didn't notice, and no one was seen to mourn, does not make the sudden extinction any less of a fact.. Modern Architecture died in St Louis, Missouri on July 15, 1972 at 3:32 p.m. (or thereabouts) when the infamous Pruitt-Igoe scheme, or, rather several of its slab blocks were given the final coup de grâce by dynamite. Previously it had been vandalized, mutilated and defaced...and although millions of dollars were pumped back, trying to keep it alive...it was finally put out of its misery. Boom, boom, boom. [3]

Recent research has revealed the complexity of Pruitt-Igoe's planning history, eclipsing Jencks' reductive assertions.[4] Nonetheless, the stark contrast between the housing projects' lofty aims and its rapid demise set up a productive point of comparison with Kirby Smith Hall that would productively collide the past, the present, and the near future. Thus, Kirby Smith made it possible for us to connect a situation that was for the students intimate, and close-at-hand in the context of LSU's campus, to broader conversations about the agency of architecture, as well as its entanglement with social and political ideologies-and their subsequent collapse. As a result, Kirby Smith became the protagonist for a series of exercises that introduced students to the rudiments of architectural drawing, scale, and line weights. It subsequently became the site for the students' very first architectural design as understood in the traditional sense, comprising of projected section cuts, elevations, and models.

Students were asked to design a space for four people carved itself into, as well as protruded from the modernist tower. In itself this act of parasitic architecture demanded a partial deconstruction of what was already there. Echoing the carving of the squash, it made palpable to students that architectural design, or the act of articulating space, entails, at least in part, an implicit disarticulation of an existing condition. In the case of Kirby Smith, this meant that the students' space-making interventions would produce a deliberate rupture within the highly-regulated grid of the tower's structural logic. (Figure 6) Our intention here was to nudge students towards a design process in which additive form-making was intimately tied with a process of removal and of carving-out, all the while prompting them to consider the design opportunities that presented themselves in their selected placement within Kirby Smith.

Students were asked to design the space with a specific activity in mind and a compelling light condition that would be appropriate for

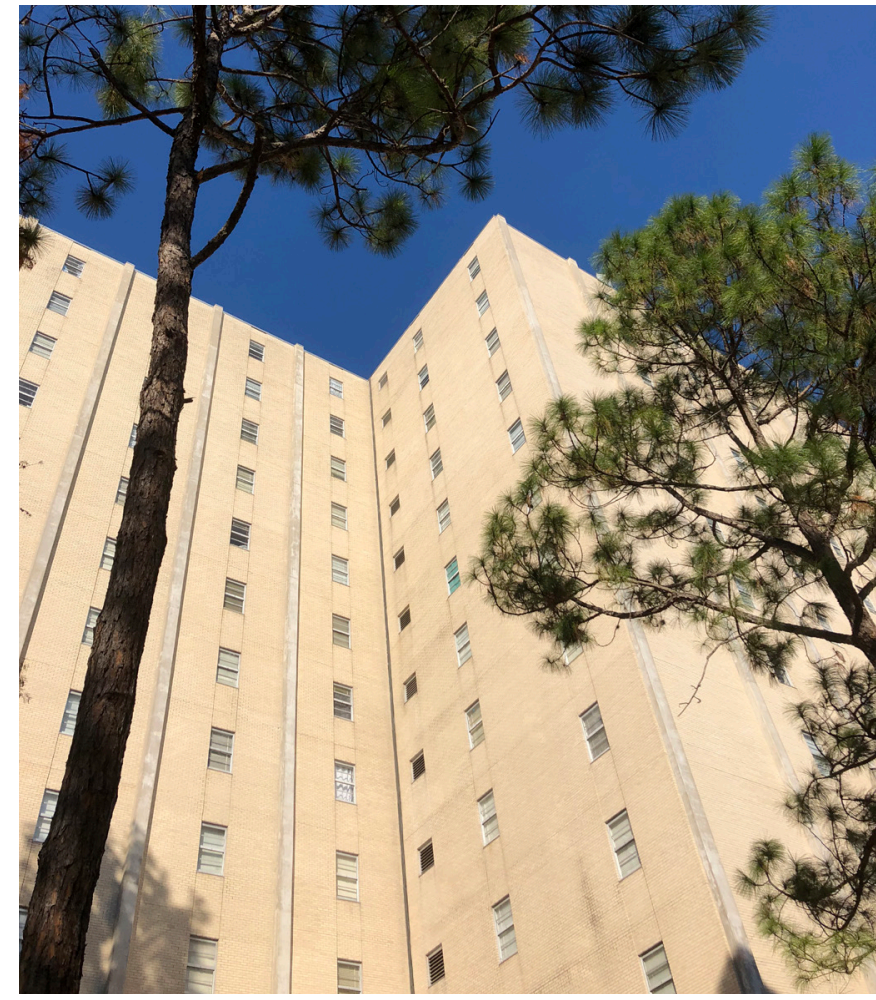

Figure 4. Kirby Smith Hall, Louisiana State University. (Photograph by authors)

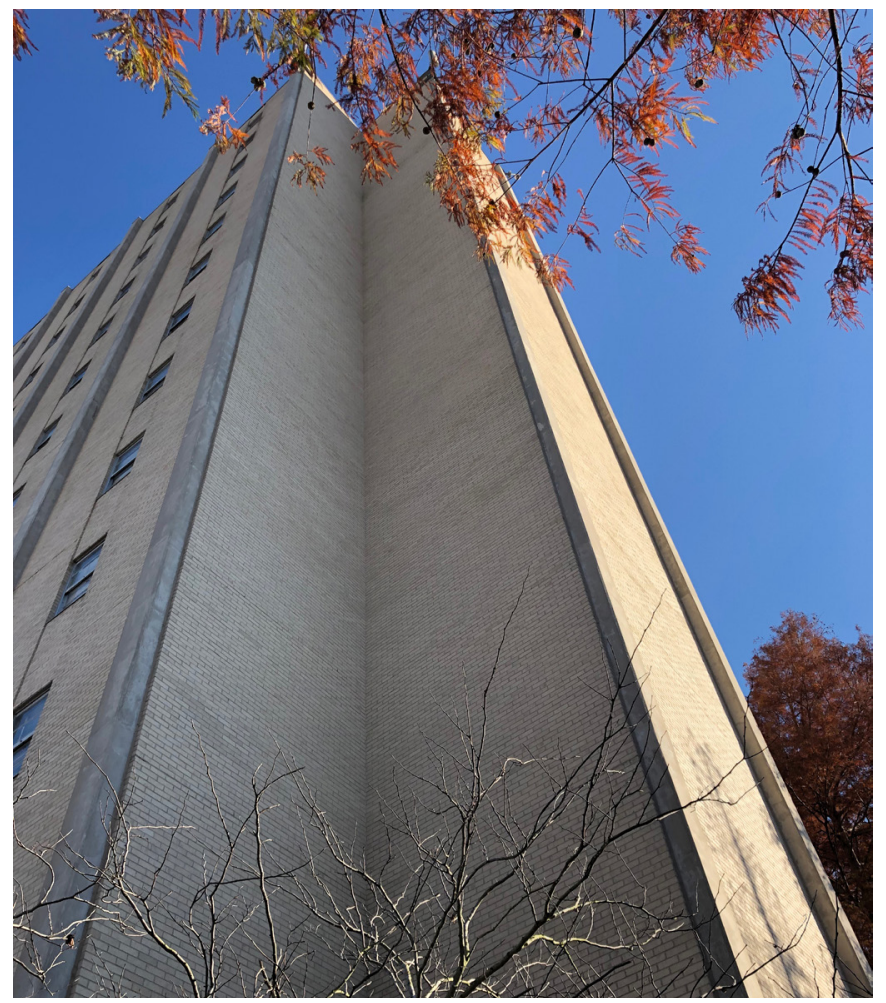

Figure 5. Kirby Smith Hall, Louisiana State University. (Photograph by authors) 


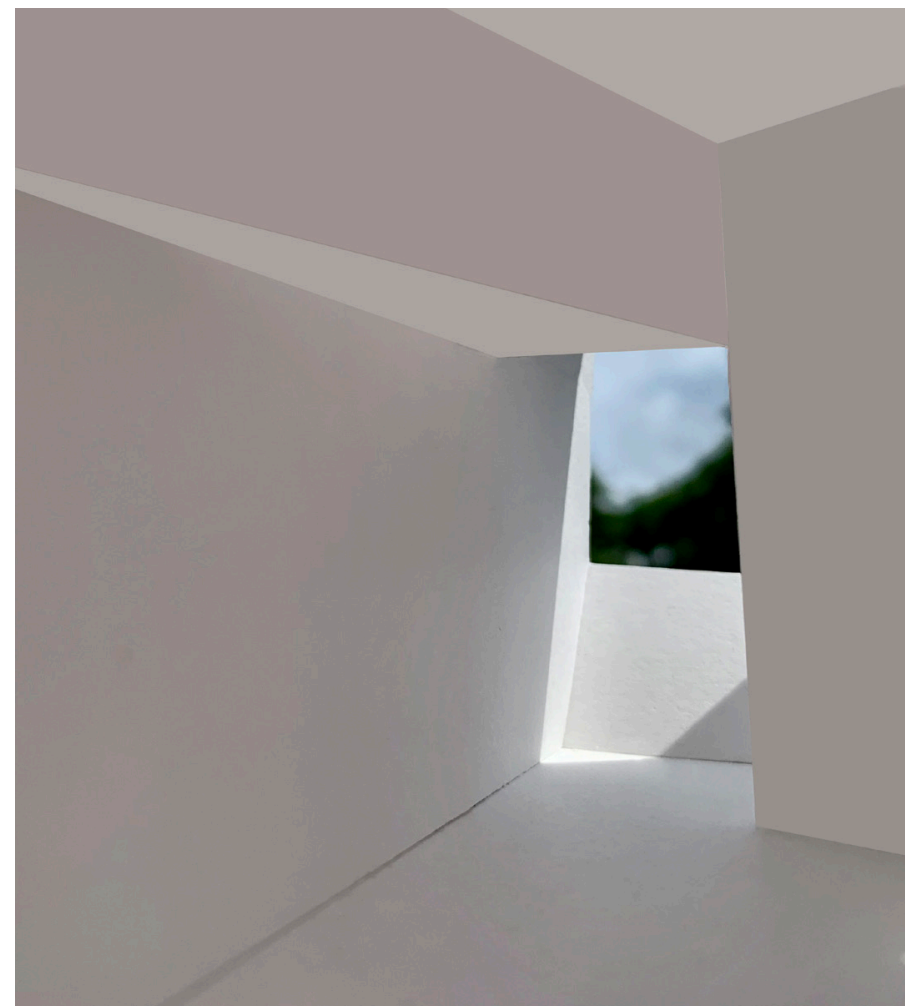

Figure 6. Student work: interior perspective of Kirby Smith intervention (Photograph by ARCH 1002 student)

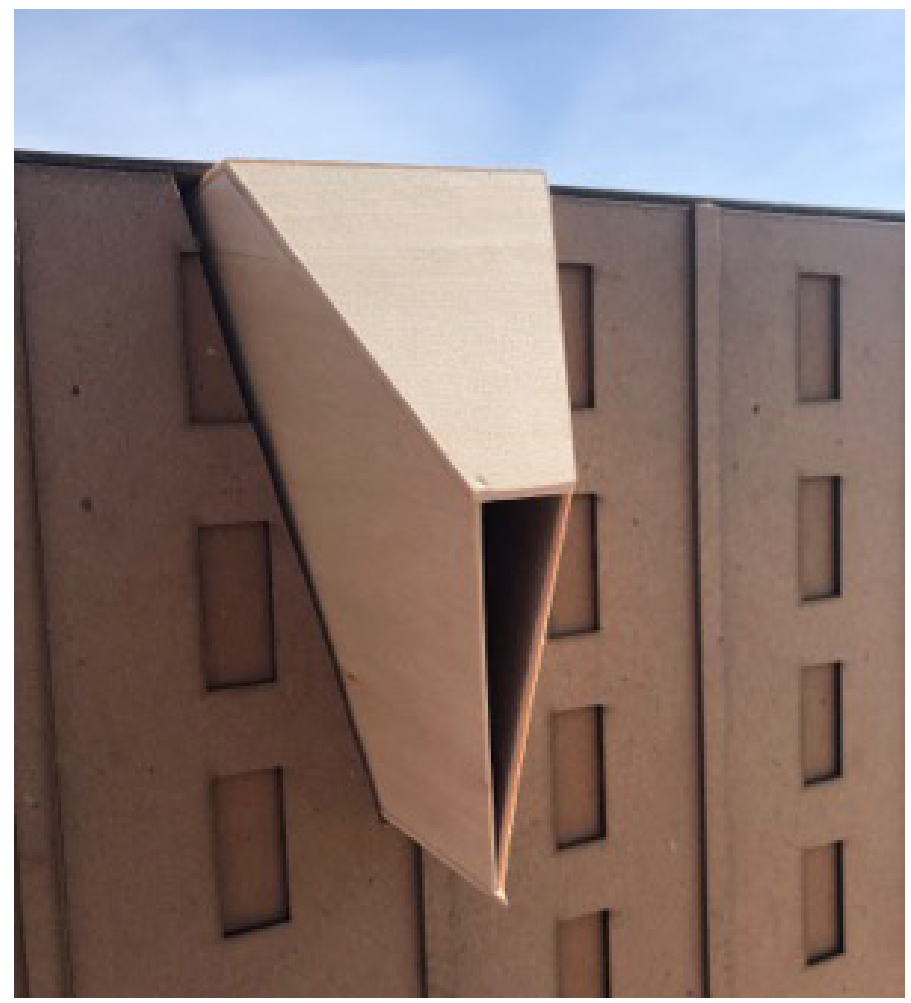

Figure 7. Student work: interior perspective of Kirby Smith intervention (Photograph by ARCH 1002 student) this activity. They were pushed to be very thoughtful about the phenomenal qualities of the space they were creating. Several became fascinated with the light quality particular at a given moment in the day, or the shifting quality of light throughout the day. Some students became absorbed by an interest to create a delicate lace-like envelope that filtered the light but was also responsive to the wind. Some were interested in the acoustic qualities of the space they created, and began to even be specific about materiality. One student designed a space for reading that celebrated the sound and flow of rain. Another student positioned their intervention in relation to the treetop of a nearby tree. Another student reached out of Kirby Smith to make a quiet space for looking at the sky, thoughtfully framed to be observed from a position of relaxed repose. Overall the projects echoed the carving of the squash in that they were working with a found architectural condition within which they had to intervene through a double process that involved both building and carving, construction and partial demolition. Students made specific decisions with respect to the location of their parasitic intervention, deeming them either dispensable or profitable. This act, even if it may have not always been explicit, opened up questions about value, found opportunities, and creative agency.

As a grand finale students were asked to design the unbecoming of their architectural interventions and contiguous Kirby Smith. This unconventional proposition was both daunting and exhilarating for all involved. Students were given the choice of an unbecoming that was either fast or slow. They were thus explicitly prompted to consider architectural collapse in terms of durations of time, as well as to make specific decisions with respect to the agency of the destructive mechanism to be set in motion. Working with two sheets of double-sided mylar - for a total of four potential time framesstudents essentially opted between the swift force of a cataclysmic event and an imagined entropy of ruination and slow decay: a designed collapse that entailed various degrees of human agency, somewhere along the sliding scale between the entropy of the cucurbit and dynamiting of Pruitt-Igoe. We were surprised-and delighted-to find students who had never taken a building construction course researching the failure of different construction materials in order to better represent the fast and slow "unbecomings."

\section{A CONCLUSION ON BUILT-IN COLLAPSE}

Assuming a pedagogical hunch rooted in the need to find new ways to cultivate beginning design students' understanding of space and form, we crafted a studio that employed a series of tactics concentrating on a gradual but progressive development of spatial sensitivities. Our aim was to simultaneously mystify and demystify core underpinnings of architecture by betting on the richness of these productive collisions-whether they are spatial, representational, or historic. The resulting studio upended preconceived notionsof 


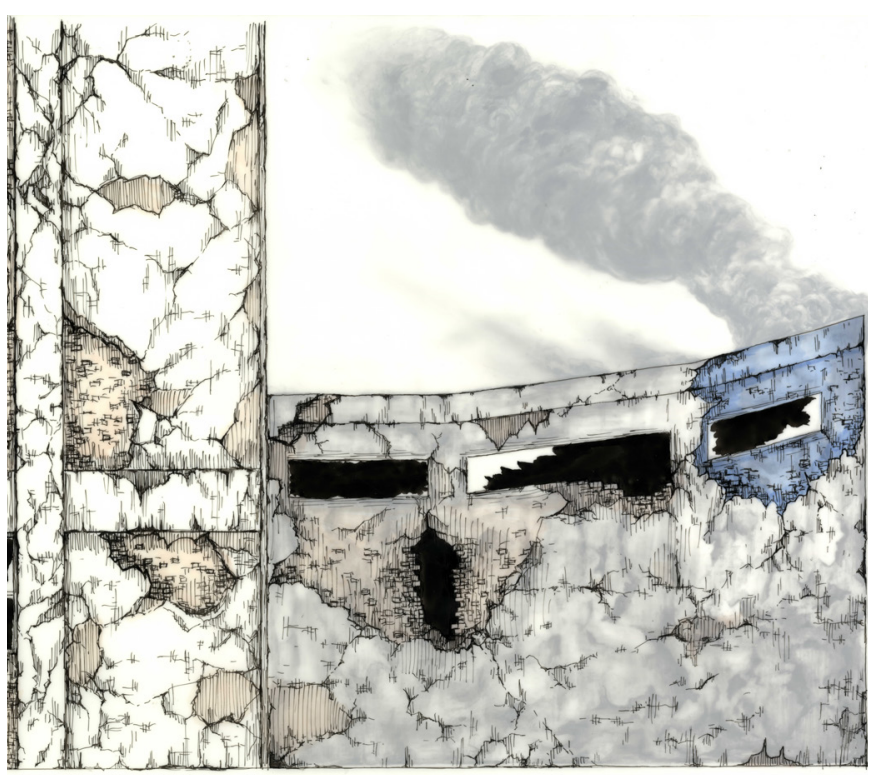

Figure 8. Student work: unbecoming of Kirby Smith on mylar (Scan by ARCH 1102 student)

architecture's disciplinary boundaries by foregrounding history, engaging the unconventional, and allowing conversations to seep beyond the expected, to consider subjects as disparate as a winter squash and Pruitt-Igoe-always organized around the radically different demands of architectural making and unmaking. We bet on the students and their interest in building up a better understanding of the world outside of themselves - leveraging curiosities to build toward enduring understandings.

In building a studio sequence around Kirby Smith's Hall impending demolition, we seized a felicitously-timed opportunity that seldom presents itself in architectural school. The series of projects surrounding Kirby Smith, as well as the exercises leading up to them, were leveraged as opportunities to see architecture as an act that entails both making and unmaking, construction and destruction, an act shaped by agencies that are not always within the control of the architect. In our case this manifested itself as understanding of entropy, both from within the material constitution of the squash and later the imagined decay of the architectural polyp, for those students who chose to engage a slow unbecoming. Questions with respect to architectural agency were especially provoked in relation to socio-political and economics-based motivations, which, can lead to obsolescence even buildings that are otherwise still functioning, as witnessed by students in infamous moments in history as well as in the intimacy of Kirby Smith Hall. Finally, students were provoked to exercise creative agency where agency is seldom exercised in architecture, namely to imaginatively orchestrate the demise of their own work.

Overall, our hunch was that Kirby Smith could operate as a fruitful instigator of design inquiry that opened a series of questions about design agency and about architecture's participation within an expanded network of forces and value-systems that are intrinsically operative within a temporal continuum-be it history, entropy, or the momentary. In reflecting on the hunches that we ourselves pursued with equal amounts of delight and trepidation we can affirm that we inadvertently sought to instill in beginning design students an approach to design that in itself imposed a subtle suspension of agency, or rather an approach to design that remained perceptive to what was already there: We nudged students to find opportunities beyond premeditated design decisions and tectonic composition. Instead, we challenged them to a delicate balancing act in which the act of "design" also entailed the practice of hunting for found circumstances, and the practice of discerning creative potentials in the close-athand and the overlooked.

We believe there is a potent lesson in confronting students with the life and dissolution of architecture beyond the intentions and control of the initial design, and likely not a more enduring architectural lesson than to eventually experience the unbecoming of an architectural project that existed as a towering presence in the students lives, and in which they invested their very first architectural design. The self-fulfilling and bittersweet predicament we as instructors are left with, is the self-destructive nature of the studio itself: a project sequence that is inherently unrepeatable once Kirby Smith Hall meets its inevitable end.

\section{Notes}

1. The Vessel, the Tower and the Ruin was the first-year studio in the Bachelor of Architecture sequence at Louisiana State University in the spring of 2019.

2. Ballard, Mark. "Kirby Smith on LSU's Campus Now One Step Closer to Being Demolished." The Advocate. August 17, 2017 https://www.theadvocate.com/baton_rouge/news/education/ article_970bce42-83a8-11e7-b6a4-efebcf11abad.html

3. Charles Jencks, The Language of Postmodern Architecture (New York: Rizzoli, 1977), 9

4. For a longer treatment of this issue, refer to Robert Fishman and The Pruitt Igoe Myth (2011). As explored in the documentary, the real problem with Pruitt-Igoe was the low occupancy rate to which the maintenance budget was pinned. This also reflected the simultaneous introduction of the FHA mortgage program that drew a growing middle class families out of the city and into the suburbs. 